\title{
Los corregimientos en el Yucatán del siglo XVI
}

\author{
The corregimientos in $16^{\text {th }}$-century Yucatán \\ Caroline Cunill \\ UNIVERSITE DU MAINE, cunillcaroline@gmail.com
}

A partir de la segunda mitad del siglo XVI, varios corregidores fueron nombrados en distintas regiones de América, este oficio se convirtió en una de las más controvertidas figuras de la administración colonial. No obstante, en la provincia de Yucatán este cargo ha permanecido prácticamente desconocido hasta la fecha de hoy. En consecuencia, el presente trabajo pretende identificar a los corregidores de Yucatán y ahondar en los motivos que empujaron a la Corona espańola a decretar su suspensión en 1580. Por otro lado, reflexionaremos sobre el salario y las funciones que fueron asignadas a aquellos oficiales, especialmente en la impartición de la justicia en la localidad. Para responder a estas interrogantes se recurrirá a distintos géneros de documentos legales, tales como los nombramientos que se entregaron a los titulares, sus probanzas de méritos y servicios y las cédulas reales por las que el Consejo de Indias trató de regular el ejercicio del cargo en Yucatán.

Palabras ClaVE: corregidores, justicia colonial, mayas, Yucatán, siglo xvI.

From the second half of the sixteenth century, corregidores, or district administrators, were appointed in several parts of Spanish America and it became one of the most controversial offices in the colonial administration. Nevertheless, this position has remained almost unstudied in the province of Yucatan. Consequently, the present article attempts, on the one hand, to identify the corregidores that were designated in this province in the second half of the sixteenth century, as well as to highlight the reasons that would lead the Spanish Crown to order the suspension of this position in 1580 . On the other hand, we will analyze the functions which were in charge of the corregidores, especially the ones relating to the administration of justice in the local level. In order to respond to those questions, a wide range of legal documentation will be used, including the appointments that were given to the corregidores, their relations of deeds and services, and the royal decrees that were aimed to control and regulate this office in Yucatan.

KeYwords: Corregidores, Colonial Justice, Mayas, Sixteenth-Century Yucatan.

Fecha de recepción del artículo: 3 de noviembre de 2014 / Fecha de aprobación: 28 de enero de 2015 / Fecha de recepción de la versión final: 23 de febrero de 2015 


\section{INTRODUCCIÓN*}

\section{unque el oficio de corregidor ha dado lugar a una historio- grafía relativamente abundante, en la provincia Yucatán este cargo ha permanecido prácticamente desconocido hasta} hoy. ${ }^{1}$ Bien es cierto que, entre 1550 y 1570 , el Consejo de Indias envió varias cédulas a los gobernadores de Yucatán para que éstos otorgaran corregimientos a vecinos beneméritos, conforme al capítulo de las Leyes Nuevas donde se mandó gratificar a los conquistadores e hijos de conquistadores con "aprovechamientos y corregimientos". Pero estos documentos oficiales no precisaban a qué corregimientos se referían, ni tenían ningún valor vinculante para las autoridades a las que iban dirigidos. Por consiguiente, es probable que ni Antonio de Corral, ni Beltrán de Cetina, ni Antonio de Garay, ni Juan Garzón fuesen designados corregidores en la provincia. ${ }^{2}$ Así, pues, según Nancy Farriss, "los mayas de Yucatán tuvieron la suerte de no depender de esos funcionarios a los que casi siempre acusaban sus contemporáneos de voraces y brutales".

* Parte del presente trabajo fue presentado en el simposio "Los indios de Nueva España ante la justicia: traducción, autoridad y mediadores culturales" organizado por Yanna Yannakakis, Luis Alberto Arrioja Díaz Viruell y Martina Schrader-Kniffi en el marco del congreso del AHILA que tuvo lugar en Berlín entre los 9 y 13 de septiembre del 2014. Por otro lado, quisiera agradecer a los lectores anónimos de la revista Relaciones Estudios de Historia y Sociedad por sus valiosas sugerencias.

${ }^{1}$ Carlos Eduardo Castañeda, "The Corregidor in Spanish Colonial Administration", Hispano-American Historical Review, vol. 9 (1929): 446-470. Guillermo Lohmann Villena, El corregidor de indios en Perú bajo los Austrias (Madrid: Ediciones de Cultura Hispánica, 1957). Woodrow Borah, coord., El gobierno provincial de la Nueva España, 1570-1787 (México: Universidad Nacional Autónoma de México, 1985). Carlos Sempat Assadourian, "Los señores étnicos y los corregidores de indios en la conformación del Estado colonial”, Anuario de Estudios Americanos, vol. 44 (1987): 325-427. Carolina M. Jurado, "Memorial cerca de la congruencia de la perpetuidad de las encomiendas de los indios. Un escrito inédito del licenciado don Francisco de Alfaro, Charcas, circa 1599. Estudio crítico y transcripción", Revista de Historia del Derecho, vol. 46 (2013): 45-71.

${ }^{2}$ Concesión de corregimiento a Antonio de Corral hijo de conquistador de Yucatán, 3 de marzo de 1553; real cédula a la Audiencia de los Confines que dé corregimientos en Yucatán a Beltrán de Cetina, 14 de febrero de 1557; real cédula al virrey y al gobernador de Yucatán en recomendación de Antonio de Garay, 12 de febrero de 1569; cédula en recomendación de Juan Garzón, 15 de febrero de 1570, en Gabriela Solís Robleda y Pedro Bracamonte y Sosa, Cedulario de la dominación española en Yucatán, siglo XVI, Colección Peninsular (Mérida: Memoria Documental, 2010), 142, 148-149, 213 y 234. 
Sin embargo, la autora matiza esta información al precisar que, para dar la vuelta a la prohibición de nombrar a corregidores declarada por real cédula del 11 de noviembre de 1580, los gobernadores de Yucatán nombraron a "equivalentes" de aquel cargo "bajo diversos títulos", como el de juez de milpa, juez de grana o juez de agravios. ${ }^{3}$ Apoyándose en la información brindada por fray Francisco de Cogolludo en su Historia de Yucatán, Manuela Cristina García Bernal señala otras dos provisiones reales, despachadas en 1588 y 1598 respectivamente, en las que la Audiencia de México volvía a prohibir estos cargos. ${ }^{4}$ Pero estas afirmaciones generan, a su vez, varias interrogantes. ¿Por qué la Corona española habría experimentado la necesidad de prohibir un oficio que, supuestamente, no existía en la provincia? ¿Cuál fue el vínculo que establecieron los actores históricos entre los cargos citados por Farriss y el de corregidor? ¿No habría que incluir en esta lista el oficio de teniente de gobernador que ocupó el maya Gaspar Antonio Xiu entre 1571 y 1573? ¿Fueron respetadas las órdenes por las cuales la Corona mandó suspender a los corregidores de Yucatán? Y, si fue el caso, ¿¿durante cuánto tiempo? El presente trabajo trata de contestar a estas preguntas, estableciendo una cronología de la ocupación del cargo en el Yucatán de la segunda mitad del siglo XVI, definiendo las funciones que fueron confiadas a estos oficiales y, finalmente, ahondando en los motivos que pudieron empujar a la Corona española a decretar su suspensión en 1580 y a repetir esta orden en 1588 y 1598.

${ }^{3}$ Nancy Farriss, La sociedad maya bajo el dominio colonial. La empresa colectiva de supervivencia (México: Consejo Nacional para la Cultura y las Artes, 2012), 126. Cédula real al gobernador de Yucatán para que quite los corregidores de indios y haga justicia de agravios, Badajoz, 11 de noviembre de 1580, en Solís Robleda y Bracamonte y Sosa, Cedulario, 383.

${ }^{4}$ Manuela Cristina García Bernal, "El gobernador de Yucatán Rodrigo Flores de Aldana”, en Economía, politica y sociedad en el Yucatán colonial (Mérida: Universidad Autónoma de Yucatán, 2005), 149-251. Este artículo también fue publicado en Homenaje al Dr. Antonio Muro Orejón, vol. 1 (Sevilla: Facultad de Filosofía y Letras de la Universidad de Sevilla, 1979), 126-127. Fray Francisco Diego López de Cogolludo, Historia de Yucatán, lib. vII, cap. XI y xv y lib. x, cap. VII, vol. 1, 5 a ed. Prólogo, notas y acotaciones por José Ignacio Rubio Mañé (México: Edición Academia Literaria, 1957), 403-404, 413-414 y 562. 


\section{Cronología de la ocupación Del CARgo DE CORREGIDOR EN YUCATÁN}

Parece que el primer nombramiento de corregidor fue otorgado al descendiente de los Xiu de Maní, Gaspar Antonio Chi, por el gobernador Diego de Santillán en 1571. En efecto, aunque no se ha localizado el nombramiento, el mismo Gaspar Antonio aseguró en su probanza de méritos y servicios haber servido como "teniente de gobernador de los pueblos de Maní y Ticul y su provincia” entre 1571 y $1573 .{ }^{5}$ Si bien este aspecto de la carrera de Gaspar Antonio es conocido por los especialistas del Yucatán colonial, ninguno de ellos ha llegado a asociar el oficio de "teniente de gobernador" con el de corregidor. ${ }^{6}$ Sin embargo, en una carta de 1573, analizada por Sergio Quezada en su trabajo sobre los caciques mayas de Yucatán, el defensor de indios Francisco Palomino no sólo asimiló el oficio de Gaspar Antonio con el de corregidor -además de referirse a la existencia de otro corregimiento en la región de Calkiní-, sino que también impugnó aquella designación. Según Quezada, esta misiva debió de empujar al gobernador don Diego de Santillán a que cesara a Gaspar Antonio de sus funciones o a que éste abandonara voluntariamente su oficio en $1573 .^{7}$ Parece legítimo, por lo tanto,

${ }^{5}$ Undécima pregunta del interrogatorio presentado por Gaspar Antonio en su probanza de méritos y servicios de 1579-1580. Archivo General de Indias (en adelante, AGI), México 104, R. 3. Este documento fue transcrito y publicado por Sergio Quezada y Anabel Torres Trujillo, Tres nobles mayas yucatecos (Mérida: Instituto de Cultura de Yucatán, 2010).

${ }^{6}$ Thomas Hillerkuss, "Los méritos y servicios de un maya yucateco principal del siglo Xvi y la historia de sus probanzas y mercedes", Revista de Historia Novohispana, vol. 13 (1993): 9-39. Sergio Quezada, Pueblos y caciques yucatecos, 1550-1580 (México: El Colegio de México, 1993), 149. Matthew Restall, "Gaspar Antonio Chi: Bridging the Conquest of Yucatán", en The human Tradition in Colonial Latin America, ed. Adrien Kenneth J., 6-21. Wilmington: Scholarly Ressources, 2002.

${ }^{7}$ Carta de Francisco Palomino al rey, Mérida, 28 de marzo de 1573, en el pleito de Carlos Arellano, en nombre y como procurador de la ciudad de Mérida, con Francisco Palomino, defensor de los indios, sobre la carta que escribió a Su Majestad en deshonor de dichas provincias, 1579. AGI, Justicia 1016, N. 11, fols. 1150-1155. Sergio Quezada comete un error tipográfico cuando localiza esta carta en el legajo 1061 de la sección Justicia del Archivo General de Indias. Sergio Quezada, Pueblos y caciques, 149. 
incluir a los tenientes de gobernadores en la lista de oficios que Farriss asimila con el cargo de corregidor.

Pero la renuncia del descendiente de los Xiu de Maní no significó que desapareciera el cargo de corregidor en la península de Yucatán. En efecto, el 30 de diciembre de 1573, Juan de Rivas fue designado corregidor de Maní y Calotmul por el gobernador don Francisco Velázquez de Gijón. ${ }^{8}$ Además, gracias a la probanza de méritos y servicios que elaboró en 1576, este titular obtuvo que el Consejo de Indias ordenara que los oficiales reales de Yucatán le pagasen "lo corrido del tiempo que ha servido conforme al título que le dio Francisco de Gijón". No obstante, el nombramiento también generó cierta suspicacia, dado que la Corona ordenó al virrey de Nueva Espańa, don Martín Enríquez, que informara de "qué corregimiento es éste de Maní y Calotmul y si conviene que le haya y si será perpetuo o temporal y qué salario se podrá dar al tal corregidor y por qué tiempo". ' Ahora bien, Juan de Rivas siguió recibiendo una ayuda de costa de un valor de 200 pesos anuales hasta su fallecimiento en 1588. ${ }^{10}$ Pero es probable que el cobro de este subsidio hubiese acabado por ser independiente del ejercicio del cargo de corregidor, otorgado en recompensa por sus servicios en las conquistas de la Nueva Galicia, Yucatán, Perú y Chile y por tener casa poblada, una situación que, según García Bernal, era relativamente común en Yucatán. ${ }^{11}$

Y es que el 11 de noviembre de 1578 Juan de Sanabria fue nombrado, a su vez, corregidor de Maní y Calotmul por el gobernador

${ }^{8}$ Nombramiento de corregidor de Maní y Calotmul otorgado a Juan de Rivas por el gobernador don Francisco Velázquez de Gijón, Mérida, 30 de diciembre de 1573, en la probanza de méritos y servicios de Juan de Rivas, 1576. AGI, Patronato 74, N. 2, R. 4.

${ }^{9}$ Real cédula para que se pague a Juan de Rivas el salario de corregidor de Maní y Calotmul, 5 de marzo de 1577, en Solís Robleda y Bracamonte y Sosa, Cedulario, 321322. Si bien no se ha podido localizar la cédula destinada al virrey, dicha información puede leerse en las anotaciones que hizo el relator del Consejo de Indias en la probanza de méritos y servicios de Juan de Rivas (1576), cit., fol. 2.

${ }^{10}$ Cuentas de la Real Hacienda de Yucatán. AGI, Contaduría 911, fols. 309, 355, 380v., 416v.-417.

${ }^{11}$ Manuela Cristina García Bernal, "Una sociedad subsidiada: las ayudas de costa en el Yucatán colonial, siglo xvi”, en Orbis Incognitus. Avisos y legajos del Nuevo Mundo. Homenaje al profesor Luis Navarro García, ed. Fernando Navarro Antolín, 155-189 (Huelva: Universidad de Huelva, 2007). 
don Guillén de las Casas. En realidad, esta designación se efectuó por estar preso su predecesor en el cargo, Rodrigo Descalona, por mandado de la Audiencia de México. ${ }^{12}$ Por consiguiente, se colige que Juan de Rivas debió de abandonar el oficio de corregidor en 1577, poco después de recibir la confirmación real para que se le pagara su ayuda de costa; en su lugar fue nombrado Rodrigo Descalona, el cual fue sustituido por Juan de Sanabria a finales de 1578. Si bien la causa de la suspensión de Rodrigo Descalona no se menciona en el nombramiento de su sucesor, probablemente tuvo que ver con la queja que presentó el licenciado Frías Quijada ante el obispo fray Diego de Landa en marzo de 1578 acerca de la conducta indebida del corregidor de Maní hacia el guardián del convento del mismo pueblo. ${ }^{13}$

En su probanza de méritos y servicios Juan de Sanabria afirmó que ocupó el cargo de corregidor de Maní y Calotmul durante más de siete ańos, primero de 1578 a 1583 y, posteriormente, de 1588 a 1591. Esta información indica que la suspensión de los corregidores de Yucatán, decretada por real cédula del 11 de noviembre de 1580, se aplicó en la provincia con un retraso de tres años, asunto sobre el que volvemos a continuación. ${ }^{14}$ Ahora bien, Juan de Sanabria volvió a ser designado corregidor de Maní y Calotmul por el gobernador Antonio de Voz Mediano en 1588, cargo al que renunció en 1591 cuando recibió un nombramiento de protector de los indios de Yucatán. ${ }^{15}$ En definitiva, se puede argüir que el corregimiento de Maní y Calotmul fue ocupado de forma casi continua por Gaspar Anto-

${ }^{12}$ Nombramiento de corregidor de Maní y Calotmul otorgado a Juan de Sanabria por el gobernador don Guillén de las Casas, Mérida, 11 de noviembre de 1578, en la probanza de méritos y servicios de Juan de Sanabria, 1612. AGI, México 224, N. 9.

${ }^{13}$ Carta del licenciado Frías Quijada a fray Diego de Landa, obispo de Yucatán, Tahuman, 31 de marzo de 1578. AGI, México 102, R. 3.

${ }^{14}$ Cédula real al gobernador de Yucatán para que quite los corregidores de indios y haga justicia de agravios, Badajoz, 11 de noviembre de 1580, cit.

${ }^{15}$ Nombramiento de corregidor de Maní y Calotmul otorgado a Juan de Sanabria por el gobernador don Antonio de Voz Mediano, Mérida, 12 de febrero de 1588 y nombramiento de protector y defensor de los indios a Juan de Sanabria hecho por el gobernador de Yucatán, Antonio de Voz Mediano, Mérida, 11 de octubre de 1591, en Juan de Sanabria, protector y defensor de los indios de las provincias de Yucatán, sobre que se le dé título y confirmación del dicho oficio (1597). AGI, México 116. 
nio Chi (1571-1573), Juan de Rivas (1573-1577), Rodrigo Descalona (1577-1578) y Juan de Sanabria (1578-1583 y 1588-1591). Pese a las mencionadas prohibiciones de 1580, 1588 y 1598, los gobernadores de Yucatán siguieron nombrando a los corregidores en el siglo xvir. García Bernal ha demostrado, en efecto, que el cargo reapareció bajo las denominaciones sucesivas de jueces de grana, capitanes a guerra y jueces repartidores, lo que obligó a la Corona española a promulgar nuevas suspensiones en 1627,1629 y $1654 .{ }^{16}$

Además, la provincia de Maní y Calotmul no fue la única donde existieron corregimientos en Yucatán. Ya se ha mencionado que, en su carta de 1573, el defensor Francisco Palomino aludió a la presencia de un corregimiento en la región de Calkiní. ${ }^{17}$ Algunos años más tarde, el mismo defensor también denunció las exacciones de un Juan López de Moy, "corregidor de los pueblos de la guardianía de la ciudad de Mérida y Concal”, información que fue retomada en la citada cédula de suspensión de $1580 .{ }^{18}$ Por otro lado, Antón Ruiz fue nombrado corregidor del pueblo de indios de Campeche por la Real Audiencia de los Confines, cargo que desempeñó entre 1548 y 1550, fecha en la que los alcaldes ordinarios de San Francisco de Campeche le tomaron residencia. ${ }^{19}$ Finalmente, Feliciano Bravo trasladó en su probanza de méritos y servicios el proveimiento de corregidor de Calkiní, Tixchel, Champotón, Acalán y Campeche que le dio el gobernador Guillén de las Casas en 1582 para reducir a los "indios infieles de la provincia de Lacandón y Tabasco y Verapaz" y "abrir camino así en las provincias de Chiapa y Tabasco como para la tierra nueva que se le manda descubrir" ${ }^{20}$ Feliciano Bravo ya

${ }^{16}$ García Bernal, “El gobernador de Yucatán”, 153-155.

${ }^{17}$ Carta de Francisco Palomino al rey, Mérida, 28 de marzo de 1573, cit.

${ }^{18}$ Real cédula al gobernador de Yucatán para que quite los corregidores de indios y haga justicia de agravios, Badajoz, 11 de noviembre de 1580, cit.

${ }^{19}$ Nombramiento de corregidor del pueblo de Campeche otorgado a Antón Ruiz por la Real Audiencia de los Confines, Ciudad de Gracias a Dios, 4 de noviembre de 1548 y residencia que tomaron al titular los alcaldes ordinarios de la villa de Campeche el 21 de julio de 1550, en la probanza de méritos y servicios de Antón Ruiz, 1552. AGI, México 96, R. 2.

${ }^{20}$ Proveimiento de corregidor hecho en Feliciano Bravo por el gobernador don Guillén de las Casas, Mérida, 30 de agosto de 1582, en la probanza de méritos y servicios de Feliciano Bravo, 1586. AGI, México 109, R. 4, fols. 24v-26r. 
había participado, junto con el padre fray Pedro Lorenzo, en una jornada "de pacificación" en aquella zona, pero es probable que el gobernador Guillén de las Casas quisiera revalidar el proyecto mediante el citado nombramiento. De hecho, Feliciano Bravo, que fue escribano de gobernación de Yucatán hasta 1575, gozaba del favor de las autoridades locales y metropolitanas desde hacía varios años, dado que recibió varias cédulas de recomendación, una ayuda de costa y una encomienda de indios situada en la Chontalpa. ${ }^{21}$

\section{ACerca de las funciones de los Corregidores DE YuCATÁN}

Ahora bien, ¿cuáles fueron las razones que justificaron la designación de corregidores en la provincia de Yucatán? Y ¿qué funciones les fueron confiadas? Para tratar de responder a estas preguntas, nos remitiremos a la información contenida en los cuatro nombramientos otorgados por la Real Audiencia de los Confines en 1548 y por los gobernadores Francisco Velázquez de Gijón, Guillén de las Casas y Antonio de Voz Mediano en 1573, 1578 y 1588, respectivamente. Según aquellos documentos, la principal misión que debían cumplir los corregidores consistía en cobrar el tributo indígena en los pueblos de indios que quedaron bajo el poder de la Corona españo-

${ }^{21}$ Señalamiento de ayuda de costa de 100 pesos de minas y 100 fanegas de maíz por don Diego de Quijada, 1565; confirmación del señalamiento por el gobernador don Luis Céspedes de Oviedo, 1567; acrecentamiento de ayuda de costa a cumplimiento de 150 pesos de minas y 150 fanegas de maíz por don Luis Céspedes de Oviedo, 1569; y otorgamiento de una encomienda de indios por el citado gobernador, 1570, en la probanza de méritos y servicios de Feliciano Bravo (1578). AGI, México 100, R. 4. Feliciano Bravo también recibió el apoyo de la Corona española que promulgó, en 1572 y 1580 , dos cédulas para que este vecino fuese favorecido por las autoridades de Yucatán. La primera se encuentra en la probanza de 1578 y la segunda en Solís Robleda y Bracamonte y Sosa, Cedulario, 384-385. Sobre Feliciano Bravo véanse también Manuela Cristina García Bernal, Población y encomienda en Yucatán bajo los Austrias (Sevilla: Consejo Superior de Investigaciones Científicas, Escuela de Estudios Hispanoamericanos, 1978), 207-329 y "Una sociedad subsidiada”, 174. Cabe subrayar que la titularidad de la encomienda le fue impugnada a Feliciano Bravo por Antón Ruiz. Sobre este aspecto, consúltese Caroline Cunill, "La frontera en el discurso de los caciques chontales, siglo Xvı", en Poblar la inmensidad: sociedades, conflictividad y representaciones en los márgenes del Imperio Hispánico (siglos XV-XIX), coord. Salvador Bernabeu Albert (Sevilla: csIC, 2010), 209-230. 
la después de decretarse la expropiación de las encomiendas del Adelantado Montejo y de su mujer e hijos en 1548. Cabe subrayar, en efecto, que las comunidades indígenas de Campeche, Maní y Ticul se encuentran en la lista de los pueblos que, según García Bernal, estuvieron administrados por la Corona española a partir de 1548, a saber, Yaxkukul, Telchac, Cusama, Maní, Ticul, Champotón, Campeche, Sabanal, Kini y Tecoh. ${ }^{22}$

Así, pues, en el nombramiento que la Real Audiencia de los Confines entregó a Antón Ruiz en 1548 se estipuló que este corregidor debería tener "cargo y cuidado de cobrar los tributos que los naturales dieren del dicho pueblo [de Campeche] que son obligados a dar conforme a la tasación que de ello está hecha y acudir con ellos a los nuestros Oficiales de la dicha provincia de Yucatán". ${ }^{23}$ Del mismo modo, en 1573, el gobernador Francisco Velázquez de Gijón le ordenó a Juan de Rivas que cobrara a los "naturales de los pueblos de Maní y Ticul, que están en la Real Corona, los tributos que están obligados a dar por tasa, los cuales enviaréis a sus tiempos a los dichos jueces oficiales para que se vendan y beneficien", orden que fue reiterada en los nombramientos que recibió Juan de Sanabria en 1577 y 1588 , respectivamente. ${ }^{24} \mathrm{El}$ corregidor aparece, por consiguiente, como una especie de "sustituto real" de la figura del encomendero en los pueblos de indios administrados por la Corona.

No obstante, se observa un ligero desfase entre la lista de las comunidades mayas administradas por la Corona, por un lado, y los territorios que abarcaron los corregimientos de Yucatán, por otro. En efecto, si bien el corregidor de Mérida y Concal pudo hacerse cargo del tributo de los pueblos de Dzemul, Kini, Telchac y Yaxkukul, no pudo hacer lo propio en Concal, Chuburnú, Mocochá, Nolo y Tixkokob, encomiendas de Francisco de Montejo. Lo mismo se observa en la región de Calkiní, cuyas comunidades esta-

${ }^{22}$ García Bernal, Población y encomienda, 201-204.

${ }^{23}$ Nombramiento de corregidor otorgado a Antón Ruiz, Ciudad de Gracias a Dios, 4 de noviembre de 1548 , cit.

${ }^{24}$ Nombramiento de corregidor otorgado a Juan de Rivas, Mérida, 30 de diciembre de 1573, cit. Nombramiento de corregidor de Maní y Calotmul otorgado a Juan de Sanabria, Mérida, 11 de noviembre de 1578, cit. Nombramiento de corregidor de Maní y Calotmul otorgado a Juan de Sanabria, Mérida, 12 de febrero de 1588, cit. 
ban encomendadas en Francisco Pérez, Pedro Martín, Francisco Quiroz y Gregorio Cetina, respectivamente. Finalmente, Calotmul tampoco estaba administrado por la Corona, sino por el encomendero Rodrigo Álvarez..$^{25}$ Ello sugiere que, en realidad, el cobro del tributo sólo constituía una de las misiones del corregidor, quien también asumió la función de hacer justicia en los territorios bajo su jurisdicción. Esto permite explicar la oscilación que se observa en los nombramientos que fueron otorgados a los corregidores de Maní. Cabe recordar que en su probanza de méritos y servicios Gaspar Antonio Chi se refirió a su cargo de "teniente de gobernador en las provincias de Maní y Ticul", siendo ambos pueblos administrados por la Corona. En cambio, en el nombramiento que dio a Juan de Rivas, el gobernador Francisco Velázquez de Gijón habló de "Maní y Ticul" únicamente cuando evocó el cobro del tributo indígena; en el resto del documento se refirió a "las provincias de Maní y Calotmul". En este caso, el gobernador designaba, por lo tanto, la jurisdicción que quedaba bajo la autoridad del corregidor Juan de Rivas.

De hecho, la función de representante de la justicia real aparece claramente en los cuatro nombramientos que hemos localizado. Así, pues, en 1548 la Real Audiencia de los Confines le dio a Antón Ruiz vara de justicia con "jurisdicción civil y criminal" para oír y determinar "los pleitos y causas que en él [el pueblo de indios de Campeche] acaecieren en cualquier manera por vuestros mandamientos y sentencias disruptivas". Sin embargo, el corregidor tenía que remitir las apelaciones que se interpusiesen a la Audiencia y, en los "casos arduos" donde hubiese "efusión de sangre o mutilación de miembro o vergüenza pública", debía hacer información, prender a los "delincuentes que parecieren por ella culpados $y$, presos a buen recaudo, juntamente con la dicha información”, enviarlos a la Audiencia "para que en ella se provea lo que sea justicia". Según el documento, en efecto, era conveniente que los casos arduos "se determinen por personas de letras e experiencia". ${ }^{26}$ Del mismo modo, el principal argumento al que recurrió el gobernador Francisco Velázquez de

${ }^{25}$ García Bernal, Población y encomienda, 479-533.

${ }^{26}$ Nombramiento de corregidor otorgado a Antón Ruiz, 4 de noviembre de 1548, cit. 
Gijón para proveer de corregidor a la región de Maní y Calotmul fue el alejamiento de la ciudad de Mérida, que dificultaba el correcto desenvolvimiento de la justicia real en la zona. Según él, esta situación de impunidad podía originar "alguna rebelión y alzamiento contra el servicio de Su Majestad”, de modo que le encargó a Juan de Rivas que tuviera en justicia a los naturales y a los españoles que en las provincias Maní y Calotmul

estuvieren o vinieren y anduvieren, conociendo de cualesquier causas civiles y criminales que han sucedido y suceden en las dichas provincias y pueblos de ellas así entre los españoles como mestizos y negros y mulatos como entre los dichos naturales, determinando y sentenciando sus causas conforme a justicia y a la instrucción que por ello vos será entregada emanada de mi nombre. ${ }^{27}$

Por otro lado, y aunque este aspecto no aparece en los nombramientos consultados, es probable que, como señala García Bernal, los corregidores se dedicaran al repartimiento de mercancías entre los indígenas. Esta práctica consistía en "adelantar dinero o artículos diversos a los mayas para que éstos los devolvieran en patíes, mantas, cera grana, hilo, etc.", lo que, según la autora, "acabó siendo otra forma más de explotación de la mano nativa por los gobernadores". ${ }^{28}$ En realidad, esta función fue precisamente uno de los puntos en común que tuvieron los corregidores con los jueces de grana y los jueces repartidores que fueron nombrados por los gobernadores de Yucatán en el siglo XVII y que la Corona espańola trató de erradicar por diversas órdenes. ${ }^{29}$ Finalmente, cabe recalcar que, si bien los nombramientos de corregidor de Yucatán siguieron un patrón común, también se amoldaron a las condiciones específicas que imperaban en las regiones donde los futuros titulares habrían de ejercer sus cargos.

${ }^{27}$ Nombramiento de corregidor otorgado a Juan de Rivas, 30 de diciembre de 1573, cit. Desgraciadamente, desconocemos el paradero de la instrucción para los corregidores que menciona el gobernador Francisco Velázquez de Gijón. No obstante, este texto pudo asemejarse al que recoge Diego de Encinas en su Cedulario indiano, vol. 3 (Madrid: Ediciones de Cultura Hispánica, 1945), 17-19.

${ }^{28}$ García Bernal, “El gobernador de Yucatán”, 149-150.

${ }^{29}$ Ibidem. 
De este modo, en el nombramiento entregado a Antón Ruiz, la Audiencia hizo hincapié en el hecho de que los naturales del pueblo de Campeche, por estar situado éste en el Camino Real, eran víctimas de frecuentes abusos por parte de los "caminantes y otras personas que por él van y pasan", pues, "les toman sus haciendas y mantenimientos que tienen sin se los pagar y los cargan por fuerza y contra su voluntad aunque les paguen y hacen otras cosas indebidas", por lo que se pidió al corregidor que tuviera especial cuidado en este asunto. ${ }^{30}$ Por su lado, el gobernador Francisco Velázquez de Gijón insistió tanto en la presencia de numerosos españoles en la región de Maní y Calotmul, como en el importante volumen de "tratos y contratos" que éstos realizaban con la población maya, negocios que originaban múltiples agravios, tales como la venta de vino, la usurpación de bienes o el amancebamiento con mujeres indígenas. Y es que, si bien se promulgó a lo largo del siglo XvI una abundante normativa legal para prohibir que españoles, negros, mulatos y mestizos se asentaran en los pueblos de indios de Nueva España, la realidad se alejaba mucho de las disposiciones regias. ${ }^{31}$ En consecuencia, en defecto de poder hacer respetar un orden ideal, las autoridades de la península yucateca intentaron limitar los efectos negativos de un hecho consumado.

En definitiva, aquellas observaciones sugieren que los corregimientos sirvieron de estructuras intermedias destinadas a ejercer de forma efectiva el gobierno y la justicia en los territorios alejados de ciudad de Mérida, donde se concentraban la mayoría de las instituciones reales. En este sentido, se puede argüir que los corregimientos fueron, hasta cierto punto, la contraparte civil de las guardianías que los franciscanos implantaron en distintas regiones de la provincia yucateca. Esto, por lo tanto, nos lleva a matizar la tesis de William Hanks, según la cual las guardianías funcionaron como enlace regional para conectar a los pueblos de indios de Yucatán con la ciu-

${ }^{30}$ Nombramiento de corregidor otorgado a Antón Ruiz, 4 de noviembre de 1548, cit.

${ }^{31}$ Ejemplos de este tipo de legislación son las cédulas reales contra la presencia de negros en los pueblos de indios de Yucatán del 9 de septiembre de 1551, para que los encomenderos no residan en los pueblos de sus encomiendas del 10 de octubre de 1580, en Solís Robleda y Bracamonte y Sosa, Cedulario, 114 y 380. 
dad de Mérida, dada la falta de una estructura civil intermedia en la provincia. ${ }^{32}$ De hecho, la presente investigación demuestra que los gobernadores se preocuparon por esta cuestión y que trataron de aportarle una solución gracias al nombramiento de corregidores en zonas que se superponían con las que abarcaban las guardianías. A este respecto, no está de más señalar que los cuatro nombramientos mencionados estipulaban que el corregidor debía estar atento a la cristiandad de los indios.

Así, pues, en 1548 se le ordenó a Antón Ruiz que procurara la instrucción y conversión de los naturales del pueblo de Campeche y que hiciera que éstos se recogiesen para oír y aprender la doctrina cristiana, "prohibiendo y vedando borracheras e idolatrías y otros sacrificios gentílicos". ${ }^{33}$ Asimismo, el corregidor de Maní y Calotmul debía intentar "saber e inquirir de secreto que entre los dichos naturales no haya borrachera ni ritos antiguos y si se trata de alguna rebelión o algún alzamiento entre ellos" y dar "aviso para que yo [el gobernador Francisco Velázquez de Gijón] provea en ello lo que convenga". ${ }^{34}$ Aunque no se les dio a los corregidores jurisdicción alguna para intervenir en los asuntos religiosos, probablemente con el fin de evitar posibles conflictos con las autoridades eclesiásticas, sí se les confió un papel de supervisión en aquellos asuntos, el cual estaba directamente vinculado con las prerrogativas del gobernador de Yucatán. No cabe duda de que estas atribuciones debieron de ser vistas con recelo por parte de los franciscanos, que se mostraban particularmente celosos de su poder en la región. Esta situación bien

32 Según Hanks, "mientras que la estructura civil de los pueblos de indios los individualizó como unidades cerradas desprovistas de instituciones entre el pueblo y el gobierno provincial, las guardianías constituyeron una estructura intermedia que agrupaba a varios pueblos alrededor de la cabecera" (la traducción es mía). William F. Hanks, "Reducción and the Reforming of the Social Landscape in Colonial Yucatán", en Espacios mayas. Usos, representaciones, creencias, ed. Alain Breton, Aurore Monod-Becquelin y Mario Humberto Ruz, 170 (México: Universidad Nacional Autónoma de México, Centro de Estudios Mexicanos y Centroamericanos, 2003). Sobre la organización religiosa en el Yucatán del siglo xvi, véase también Stella María González Cicero, Perspectiva religiosa en Yucatán, 1517-1571 (México: El Colegio de México, 1978).

${ }^{33}$ Nombramiento de corregidor otorgado a Antón Ruiz, 4 de noviembre de 1548, cit.

${ }^{34}$ Nombramiento de corregidor otorgado a Juan de Rivas, Mérida, 30 de diciembre de 1573, cit. 
pudo constituir la tela de fondo del conflicto que en 1578 surgió entre el guardián del convento de Maní y el corregidor de la misma zona, Rodrigo Descalona.

Por otro lado, también es interesante observar que la jurisdicción de los corregimientos de Yucatán se superponía, a grandes rasgos, con los territorios de los principales cúuchcabalob (o provincias) prehispánicos. Bien es cierto que, como lo han demostrado tanto Tsubasa Okoshi Harada como Sergio Quezada, el concepto de cúuchcabal entre los mayas yucatecos no tenía que ver con una noción estrictamente territorial, sino que estaba fundamentado más bien en una unión basada en lazos personales entre los dirigentes de varios pueblos. En la mayoría de los casos, se trataba de lazos de parentesco entre los miembros de un linaje, pero también podían tratarse de alianzas políticas. Por lo tanto, los cúuchcabalob no forzosamente estaban integrados por pueblos que conformaban un continuum territorial. ${ }^{35} \mathrm{Si}$ bien la conquista supuso cambios radicales en la concepción del espacio político entre los mayas yucatecos, con la introducción de las encomiendas y, poco después, con las reducciones, no es menos cierto que los españoles se cuidaron de conservar algunas estructuras de gobierno de raigambre prehispánica, siendo el mejor ejemplo de ello la continuidad de algunos linajes gobernantes en el mando de sus comunidades. ${ }^{36}$

Es probable que la implantación de estructuras de gobierno intermedias, como la guardianía en la esfera eclesiástica y el corregimiento en la civil, se deba interpretar a la luz de aquella estrategia política hispana, que consistió en comprender la organización política previa a la conquista y en sustituir a las autoridades autóctonas por autoridades coloniales, ya fueran estas mayas (como ocurrió con

${ }^{35}$ Véanse Sergio Quezada, Maya Lords and Lordship: The Formation of Colonial Society, 1350-1600 (Norman: University of Oklahoma Press, 2014), 21-32; Tsubasa Okoshi Harada, “Otra lectura de la 'Memoria de la distribución de los montes (1557)' de los Papeles de los Xiu de Yaxá, Yucatán”, en Los mayas de ayer y hoy, vol. iI, eds. Alfredo Barrera Rubio y Ruth Gubler, 778-791 (Mérida: Conalculta, INAH, 2006); Tsubasa Okoshi Harada y Sergio Quezada, "Vivir con fronteras: espacios mayas peninsulares del siglo xvi", en El territorio maya. Memoria de la quinta mesa redonda de Palenque, coord. Rodrigo Liendo Stuado, 137-149 (México: Instituto Nacional de Antropología e Historia, 2008).

${ }^{36}$ Sobre estas cuestiones, véase Quezada, Pueblos y caciques y Maya Lords. 
Gaspar Antonio Chi de 1571 a 1573) o españolas (como pasó en los ańos siguientes). Así, se puede comprobar que los territorios abarcados por los corregimientos que fueron implantados en el oeste de la península yucateca en la segunda mitad del siglo XVI no distaban mucho de los tres principales cúuchcabalob prehispánicos de Calkiní, Maní y Motul. ${ }^{37}$ A este respecto, resulta reveladora la inclusión de Calotmul dentro del corregimiento de Maní, dado que Quezada explica que los cúuchcabalob de Maní y de Calotmul estaban gobernados por dos ramas del linaje Xiu y que, al tiempo de la llegada de los españoles, Ah Kukum Xiu (bautizado bajo el nombre de don Francisco de Montejo Xiu), halach uinic de Maní, se casó con María Xiu, que era hija de Ah Kukul Xiu, halach uinic de Calotmul, lo que reforzó la unidad entre ambos cúuchcabalob. ${ }^{38}$ No es extraño, por consiguiente, que el gobernador Francisco Velázquez de Gijón designara a un solo corregidor para las "provincias de Maní y Calotmul" y que esta estructura fuese retomada en los dos nombramientos posteriores que recibió Juan de Sanabria de manos de Guillén de las Casas y de Antonio de Voz Mediano, respectivamente.

\section{REFLEXIONES EN TORNO A LA SUSPENSIÓN DEL CARGO DE CORREGIDOR EN I 580}

Como es sabido, el oficio de corregidor suscitó encarnizadas polémicas y acerbas críticas en América, lo que explica porque el cargo pasó a la historia más por las notables exacciones cometidas por sus titulares, que por sus eventuales logros en el desempeńo de la justicia local. Ahora bien, una de las primeras quejas que surgieron en Yucatán con respecto a estos oficiales giró en torno a su salario. En efecto, en la citada carta que el defensor de indios Francisco Palomino

${ }^{37}$ En la estructura colonial el pueblo principal de Motul fue sustituido por el de Concal, que sirvió de cabecera tanto para la guardianía, como para el corregimiento de Mérida-Concal si seguimos la denominación propuesta por Francisco Palomino, retomada en la cédula de suspensión de 1580 .

${ }^{38}$ Quezada, Maya Lords, 22 y 126-127. Véase también el árbol genealógico de la familia Xiu y el análisis que de él hicieron Sergio Quezada y Tsubasa Okoshi Harada en Los papeles de los Xiu de Yaxá, Yucatán (México: Universidad Nacional Autónoma de México, 2001), 51 y 174. 
mandó al monarca en 1573, Palomino denunció que los 150 pesos que recibía tanto Gaspar Antonio Chi en Maní, como su homólogo en Calkiní, estaban sufragados por las comunidades indígenas de aquellas provincias. De hecho, esto constituía el principal argumento con el que Francisco Palomino pretendía que la Corona española ordenara la suspensión de los corregidores en Yucatán. El defensor añadía que si bien sus "requerimientos", presentados ante el gobernador Diego de Santillán en 1572, empujaron a que Gaspar Antonio Chi dejase de cobrar estos emolumentos, el titular seguía recibiendo numerosas dádivas por parte de los naturales. ${ }^{39}$

Aunque Francisco Palomino también logró que Gaspar Antonio fuese suspendido de sus funciones a finales de 1573, el gobernador Francisco Velázquez de Gijón se apresuró a nombrar a otro titular en su lugar. Pero, de aquel tiempo en adelante, el salario de los corregidores de Yucatán, que en aquella ocasión fue acrecentado a un valor de 200 pesos de oro de minas anuales, ya no estaría sufragado por las comunidades mayas, sino por el Real Erario de Yucatán bajo el concepto de ayuda de costa. ${ }^{40} \mathrm{El}$ único obstáculo para los beneficiarios de aquella merced era que el cobro de estos emolumentos estaba sometido a la obtención de la debida confirmación real del nombramiento. Por consiguiente, Juan de Rivas tuvo esperar hasta 1577 para recibir su ayuda de costa, ya que, gracias a la probanza de méritos y servicios que elaboró a la sazón, el Consejo de Indias mandó a los oficiales reales de Yucatán que le pagaran "lo corrido del tiempo que ha servido conforme al título que le dio Francisco Velázquez de Gijón”. ${ }^{41}$ En las cuentas del Real Erario de Yucatán correspondientes al año de 1577-1578 se puede comprobar que Juan de Rivas cobró 1,327 pesos y 4 tomines y 3 granos "por lo corrido de cuatro ańos de la ayuda de costa que le fue seńalada por Francisco Velázquez de Gijón [...] y que Su Majestad por su real cédula firmada de su real nombre fecha en Madrid a 5 de marzo de 1577 y el

${ }^{39}$ Carta de Francisco Palomino al rey, Mérida, 28 de marzo de 1573, cit.

${ }^{40}$ Nombramientos de corregidor otorgados a Juan de Rivas y Juan de Sanabria, Mérida, 30 de diciembre de 1573 y 11 de noviembre de 1578, cit.

${ }^{41}$ Real cédula para que se pague a Juan de Rivas el salario de corregidor de Maní y Calotmul, 5 de marzo de 1577, cit. 
excelente señor don Martín Enríquez [...] en su real nombre mandan se le pague". ${ }^{22}$ Juan de Sanabria enfrentó dificultades similares, puesto que no recibió salario alguno durante los siete años que desempeñó el cargo de corregidor de Maní y Calotmul, razón por la que elaboró dos probanzas de méritos y servicios en 1580 y 1602, respectivamente. ${ }^{43}$

A pesar de haber logrado que los salarios de los corregidores fuesen sufragados por la Real Hacienda, en los años siguientes Francisco Palomino no dejó de abogar por la suspensión de estos oficiales. En efecto, durante la estancia que efectuó en la Corte española entre 1579 y 1580 , el defensor volvió a abordar el asunto. ${ }^{44}$ Esta vez, sus argumentos giraron en torno a dos aspectos: por un lado, las numerosas exacciones que cometían los corregidores en contra de los indios y, por otro, la suficiencia de las autoridades locales que ya existían, los gobernadores mayas, para hacer justicia en la provincia. Según el defensor, los pueblos de indios eran "bien gobernados por sus caciques [gobernado]res indios y sin la costa y molestia que [estos corregidores] les hacen". Francisco Palomino también pidió la suspensión de los jueces que había puesto el gobernador Guillén de las Casas en "las villas de españoles de aquella provincia que son Valladolid, Campeche, Tabasco [y] Bacalar". Pretendía que "sólo sea el gobernador y su lugarteniente general letrado juez de los indios y de sus [causas] y negocios pues son de gobernación, y no otra [cualesquier] justicia”. ${ }^{45}$ Estas demandas

${ }^{42}$ Cuentas de la Real Hacienda de Yucatán. AGI, Contaduría 911, fols. 309, 355, 380v., $416 v .-417$.

${ }^{43}$ Estos dos documentos están recopilados en la probanza de méritos y servicios que Juan de Sanabria presentó en 1612. AgI, México 224, N. 9.

${ }^{44}$ Sobre las circunstancias del viaje de Francisco Palomino a la metrópoli y sus gestiones en la Corte, véase Caroline Cunill, Los defensores de indios de Yucatán y el acceso de los mayas a la justicia colonial, 1550-1600 (Mérida: Centro Peninsular en Humanidades y Ciencias Sociales, Universidad Nacional Autónoma de México, 2012), 124-126 y 231-297.

${ }^{45}$ Francisco Palomino, defensor de los indios de Yucatán, suplica se le dé sobrecédula de la que está dada para que el gobernador de aquella provincia no tenga más de un teniente letrado y quite los corregidores y alcaldes mayores que tiene puestos, 1579. AGI, Indiferente General 1390. El documento está roto en los bordes, por lo que las palabras que se encuentran entre corchetes son propuestas hechas en consideración del sentido del fragmento. 
fueron ampliamente apoyadas por los representantes de los cabildos españoles de Yucatán que en aquella ocasión también se encontraban en la metrópoli. ${ }^{46}$

Aquellas denuncias hicieron mella en la Corte española, dado que en la cédula real del 11 de noviembre de 1580 se retomó la mayoría de los argumentos esgrimidos por el defensor Francisco Palomino para justificar la orden de suspensión de los corregidores de Yucatán. ${ }^{47}$ Ahora bien, aunque esta medida respondía a preocupaciones locales, no es menos cierto que también se insertaba en un contexto político global, caracterizado por la voluntad por parte de la Monarquía hispana de racionalizar el funcionamiento de la justicia en América, especialmente en su relación con la población indígena. En efecto, a raíz del envío a América de varios cuestionarios entre 1577 y 1580, organizado en el marco de la reforma del Consejo de Indias llevada a cabo por Juan de Ovando, se multiplicaron las quejas acerca del difícil acceso indígena a la justicia real. Estas denuncias llegaron a preocupar Felipe II, quien exigió en repetidas ocasiones que sus consejeros propusieran medidas para remediar la situación. ${ }^{48}$ Así, pues, en mayo de 1582, se despacharon ocho cédulas circulares enfocadas en la cuestión de la justicia indígena, en las que se mandó a los oidores de las Audiencias americanas que suspendieran el oficio de defensor de indios, que enviaran "relación sobre las tasas de tributos que se les imponen a los indios" y que recogieran información sobre los corregidores, los alcaldes mayores,

${ }^{46}$ Petición del procurador del cabildo de la villa de Valladolid, Gutierre López, ante el Consejo de Indias, 1579. AGI, Indiferente General 1390.

${ }^{47}$ Cédula al gobernador de Yucatán para que quite los corregidores de indios y haga justicia de agravios, Badajoz, 11 de noviembre de 1580, cit.

${ }^{48}$ Sobre estas cuestiones, véase Caroline Cunill, "Philip II and Indigenous Justice: Reports, Consultations, and Royal Decrees in the 1580s", Colonial Latin American Review, en prensa. De especial interés es la cédula a Martín Enríquez, virrey del Perú, mandándole hacer una relación de todos los pueblos españoles e indios del distrito de su jurisdicción, de la forma como se administra en ellos justicia, y del ejercicio, jurisdicción y salario de los cargos de corregidores, alcaldes mayores, regidores perpetuos y otros oficios, sus títulos y nombramientos y el tiempo que los ejercen, y que envíe dicha relación junto con la de los oficios que estén vacantes al Consejo de Indias, Portalegre 5 de marzo de 1581. AGI, Indiferente General 427, L. 30, fols. 328v-329v. 
los encomenderos y los "administradores culpables de haber maltratado a los indios" para castigarlos. ${ }^{49}$

No cabe duda, por consiguiente, que la orden de suspensión de los corregidores de Yucatán, decretada a finales de 1580, se insertaba en el marco de esta política real, por la que se pretendía reducir tanto los costos relacionados con el desempeńo de la justicia en la localidad, como los abusos perpetrados en contra de la población indígena por los oficiales a quienes se había encargado esta misión, ya fueran éstos defensores de indios o corregidores. No obstante, en Yucatán la cédula de suspensión no fue aplicada hasta 1583, puesto que Juan de Sanabria ocupó el cargo de corregidor de Maní y Calotmul entre 1578 y 1583 . Es posible, en efecto, que la tarea de aplicar en la península yucateca la legislación vigente fuese confiada al oidor y visitador Diego García de Palacio, que llegó a Yucatán a finales de $1582 .{ }^{50}$ Un retraso similar se observa en la aplicación de la orden de suspensión del oficio de defensor de indios, decretada por cédula real del 27 de mayo de 1582, y que fue ejecutada en Yucatán en 1586, dado que al defensor se le confió la misión de proseguir con la visita interrumpida por el regreso del oidor Diego de Palacio

${ }^{49}$ Cédula al presidente y oidores de la Audiencia de México mandándoles que le envíen relación sobre las tasas de tributos que se les imponen a los indios y no permitan que les hagan pagar por los indios muertos o ausentes; cédula al presidente y oidores de la Audiencia de México mandándoles que se informe sobre los corregidores y alcaldes mayores de dicho distrito culpables de haber maltratado a los indios y les castiguen con rigor y que no permitan que se les obligue al servicio personal vigilando que se cumplan las cédulas dadas a su favor; cédula al presidente y oidores de la Audiencia de Santa Fe de Nueva Granada mandándoles que pongan en ejecución las disposiciones provistas a favor de los indios y que castiguen con rigor a los encomenderos y administradores que les maltraten, pues son encargados y responsables de su defensa y que envíen una información de cómo se les administra la justicia, Lisboa, 27 de mayo de 1582; cédula al presidente y oidores de la Audiencia de Santa Fe de Nueva Granada mandándoles que envíen relación sobre los agravios que reciben los indios de dicho distrito y sobre la conveniencia de enviar un visitador para remediarlo y que castiguen con rigor a los que les maltraten, Lisboa, 11 de junio de 1582. AGI, Indiferente General 427, L. 30, fol. 340, 344v.-345r., 347r.

${ }^{50}$ Acerca de la visita de Diego García de Palacio a Yucatán, véanse Manuela Cristina García Bernal, "García de Palacio y sus ordenanzas para Yucatán”, Temas Americanistas, vol. 5 (1985): 1-12 e Inés Ortiz Yam y Sergio Quezada, Visita de Diego García de Palacio a Yucatán, 1583 (México: Universidad Nacional Autónoma de México, 2009). 
a la Ciudad de México en $1583 .{ }^{51}$ A este respecto, resulta interesante llamar la atención sobre las similitudes que existieron en la posición que adoptó la Monarquía hispana de cara a los oficios de defensor y de corregidor.

A finales de los 1580, en efecto, se dio un nuevo vuelco en la política real, dado que en 1588 se volvió a nombrar a un corregidor en Maní y Calotmul y que, apenas dos años más tarde, los oficios de defensores fueron reincorporados dentro de los recién creados Juzgados Generales de Indios que se implantaron en toda la América hispana. ${ }^{52}$ Por otro lado, conviene subrayar que fue el titular del oficio de corregidor, Juan de Sanabria, quien ocupó el de protector de indios en 1591 por mandamiento del gobernador Antonio de Voz Mediano. Dada la familiaridad que tenían los corregidores con los negocios indígenas, no sorprende que los gobernadores de Yucatán optaran por escoger entre aquellos oficiales a quienes habrían de desempeñar las funciones de defensor. Conviene notar que, a la inversa, poco antes de servir como corregidor, Juan de Rivas había sido nombrado defensor de indios por el gobernador Diego de Santillán, oficio que sustentó hasta octubre de 1573, fecha en la que fue restablecido en el cargo su predecesor Francisco Palomino. ${ }^{53}$ Asimismo, Gaspar Antonio Chi había desempeñado las funciones de intérprete antes de ser designado teniente del gobernador de las provincias de Maní y Ticul y siguió siendo nahuatlato en el juzgado del gobernador de Yucatán después de su renuncia en 1573 y hasta el final de su vida. ${ }^{54}$ Estos datos corroboran las observaciones de

${ }^{51}$ Sobre este aspecto, véase Cunill, Los defensores, 132-133 y 254-269.

${ }^{52}$ Acerca de los tribunales de indios en América, véanse Woodrow Borah, El Juzgado General de Indios de la Nueva España (México: Fondo de Cultura Económica, 1985). Charles R. Cutter, The Protector de Indios in Colonial New Mexico, 1659-1821 (Albuquerque: University of New Mexico Press, 1986). Carmen Ruigómez Gómez, Una politica indigenista de los Habsburgo: el Protector de Indios en el Perú (Madrid: Ediciones de Cultura Hispánica, 1988). Diana Bonnett Vélez, El protector de naturales en la Audiencia de Quito, siglos XVII-XVIII (Quito: Facultad Latinoamericana de Ciencias Sociales, 1992). Rafael A. Flores Hernández, La protectoria de indios durante el siglo XVI (México: Plaza y Valdés, 2010). Cunill, Los defensores de indios.

${ }^{53}$ Nombramiento de defensor de indios que don Diego de Santillán hizo en Juan de Rivas, Mérida, 18 de junio de 1573, en Cunill, Los defensores, 122-123.

${ }^{54}$ Sobre el desempeño de Gaspar Antonio Chi como intérprete, véase Caroline Cunill, 
Yanna Yannakakis acerca de la porosidad que existió entre las funciones de intérprete y de representante legal de los indígenas en la Oaxaca colonial, puesto que, en muchas ocasiones, los primeros fueron conducidos a tramitar las peticiones que traducían ante las autoridades coloniales. ${ }^{55}$

\section{Consideraciones finales}

El presente estudio permite atestiguar la existencia de corregimientos en la provincia de Yucatán desde 1548, fecha en la que un corregidor fue nombrado en el pueblo de indios de Campeche. No obstante, no fue hasta la década de los 1570 cuando la institución se consolidó en la provincia, especialmente en la región de Maní y Calotmul, donde fueron designados tres corregidores entre 1571 y 1578. Pero esta zona no constituyó una excepción, puesto que en el mismo periodo el defensor Francisco Palomino reportó la presencia de corregidores tanto en la provincia de Calkiní, como en la de Concal. Si bien la principal función de los corregidores consistió en cobrar el tributo en los pueblos de indios que quedaron bajo la administración de la Corona española tras la confiscación de las encomiendas del conquistador don Francisco de Montejo y su mujer e hijos, todos los nombramientos también insistieron en el papel que debían desempeñar aquellos oficiales en el correcto desempeño de la justicia en la localidad, por lo que a los titulares se les entregaron varas de justicia. Estas estructuras de gobierno intermedias vinieron a funcionar de forma paralela a las guardianías, unidades mediante las cuales los franciscanos habían organizado la provincia en la esfera religiosa. Ambas instituciones fueron implantadas, a grandes rasgos, en los territorios que conformarían los cúuchcabalob mayas en el

\footnotetext{
"Los intérpretes de Yucatán y la Corona española: negociación e iniciativas privadas en la fragua del Imperio ibérico, siglo xvı", Colonial Latin American Historical Review, Second Series, vol. 1/4 (2013): 361-380.

${ }^{55}$ Yanna Yannakakis, "Making Law Intelligible: Networks of Translation in MidColonial Oaxaca", en Indigenous Intellectuals: Knowledge, Power, and Colonial Culture in Mexico and the Andes, ed. Gabriela Ramos y Yanna Yannakakis, 97-98 (Durham y Londres: Duke University Press, 2014).
} 
momento de la conquista espańola. Aunque las numerosas críticas que llegaron hasta el Consejo de Indias en los años 1570, aunadas a la voluntad general por parte de la Monarquía hispana de reorganizar el sistema de la justicia en América, condujeron a la Corona a suspender los corregimientos en 1580, ocho años más tarde se volvió a nombrar un corregidor en Yucatán, poniendo a un lado los motivos que habían primado tan sólo unos años antes. El incumplimiento de las órdenes reales obligó a la Audiencia de México a reiterar esta prohibición en 1588 y 1598, lo que no impidió que en el siglo XVII los gobernadores de Yucatán volvieran a designar a jueces de grana y jueces repartidores con funciones similares a las de los corregidores.

\section{BibliografíA}

Assadourian, Carlos Sempat. "Los señores étnicos y los corregidores de indios en la conformación del Estado colonial". Anuario de Estudios Americanos, vol. 44 (1987): 325-427.

BonnetT VéLez, Diana. El protector de naturales en la Audiencia de Quito, siglos XVII-XVIII. Quito: Facultad Latinoamericana de Ciencias Sociales, 1992.

BoraH, Woodrow, coord. El gobierno provincial de la Nueva España, 1570-1787. México: Universidad Nacional Autónoma de México, 1985 .

El Juzgado General de Indios de la Nueva España. México: Fondo de Cultura Económica, 1985.

Bracamonte y Sosa, Pedro y Gabriela Solís Robleda. Espacios mayas de autonomía. El pacto colonial en Yucatán. Mérida: Universidad Autónoma de Yucatán, 1996.

Castañeda, Carlos Eduardo. "The Corregidor in Spanish Colonial Administration”. Hispano-American Historical Review, vol. 9 (1929): 446-470.

Cunill, Caroline. "Philip II and Indigenous Justice: Reports, Consultations and Royal Decrees in the 1580s". Colonial Latin American Review, en prensa.

. "Los intérpretes de Yucatán y la Corona española: negocia- 
ción e iniciativas privadas en la fragua del Imperio ibérico, siglo xvı". Colonial Latin American Historical Review, Second Series, vol. 1/4 (2013): 361-380.

. Los defensores de indios de Yucatán y el acceso de los mayas a la justicia colonial, 1540-1600. Mérida: Universidad Nacional Autónoma de México, Centro Peninsular en Humanidades y Ciencias Sociales, 2012.

"La frontera en el discurso de los caciques chontales, siglo xvI". En Poblar la inmensidad: sociedades, conflictividad y representaciones en los márgenes del Imperio Hispánico (siglos XV-XIX), coord. Salvador Bernabeu Albert, 209-230. Sevilla: Consejo Superior de Investigaciones Científicas, 2010.

Cutter, Charles R. The Protector de Indios in Colonial New Mexico, 1659-1821. Albuquerque: University of New Mexico Press, 1986.

Encinas, Diego de. Cedulario indiano. Madrid: Ediciones de Cultura Hispánica, 1945.

FARrISs, Nancy. La sociedad maya bajo el dominio colonial. La empresa colectiva de supervivencia. México: Consejo Nacional para la Cultura y las Artes, 2012.

Flores Hernández, Rafael A. La protectoría de indios durante el siglo XVI. México: Plaza y Valdés, 2010.

García Bernal, Manuela Cristina. Población y encomienda en Yucatán bajo los Austrias. Sevilla: Consejo Superior de Investigaciones Científicas, Escuela de Estudios Hispanoamericanos, 1978.

. "García de Palacio y sus ordenanzas para Yucatán”. Temas Americanistas, vol. 5 (1985): 1-12.

. "Una sociedad subsidiada: las ayudas de costa en el Yucatán colonial, siglo Xvı". En Orbis Incognitus. Avisos y legajos del Nuevo Mundo Homenaje al profesor Luis Navarro García, ed. Fernando Navarro Antolín, 155-189. Huelva: Universidad de Huelva, 2007.

. "El gobernador de Yucatán Rodrigo Flores de Aldana”. En Economía, política y sociedad en el Yucatán colonial. Manuela Cristina García Bernal, 141-260. Mérida: Universidad Autónoma de Yucatán, 2005. También publicado en Homenaje al Dr. 
Antonio Muro Orejón. Vol. 1. Sevilla: Facultad de Filosofía y Letras de la Universidad de Sevilla, 1979, 123-172.

González Cicero, Stella María. Perspectiva religiosa en Yucatán, 1517-1571. México: El Colegio de México, 1978.

Hanks, William F. "Reducción and the Reforming of the Social Landscape in Colonial Yucatán”. En Espacios mayas. Usos, representaciones, creencias, ed. Alain Breton, Aurore Monod-Becquelin y Mario Humberto Ruz, 161-180. México: UnAM, CEMCA, 2003.

Hillerkuss, Thomas. "Los méritos y servicios de un maya yucateco principal del siglo Xvi y la historia de sus probanzas y mercedes". Revista de Historia Novohispana, vol. 13 (1993): 9-39.

Jurado, Carolina M. "Memorial cerca de la congruencia de la perpetuidad de las encomiendas de los indios. Un escrito inédito del licenciado don Francisco de Alfaro, Charcas, circa 1599. Estudio crítico y transcripción". Revista de Historia del Derecho, vol. 46 (2013): 45-71.

Lohmann Villena, Guillermo. El corregidor de indios en Perú bajo los Austrias. Madrid: Ediciones de Cultura Hispánica, 1957.

López de Cogolludo, Fray Francisco Diego. Historia de Yucatán. 5a. ed. Prólogo, notas y acotaciones por José Ignacio Rubio Mañé. México: Edición Academia Literaria, 1957.

Окоsнi Harada, Tsubasa. "Otra lectura de la 'Memoria de la distribución de los montes (1557)' de los Papeles de los Xiu de Yaxá, Yucatán”. En Los mayas de ayer y hoy. Vol. II, ed. Alfredo Barrera Rubio y Ruth Gubler, 778-791. Mérida: Conaculta, INAH, 2006.

Oкоsнi Harada, Tsubasa y Sergio Quezada. "Vivir con fronteras: Espacios mayas peninsulares del siglo Xvi”. En El territorio maya. Memoria de la quinta mesa redonda de Palenque, coord. Rodrigo Liendo Stuado, 137-149. México: Instituto Nacional de Antropología e Historia, 2008.

Quezada, Sergio. Pueblos y caciques yucatecos, 1550-1580. México: El Colegio de México, 1993.

. Maya Lords and Lordship: The Formation of Colonial Society, 1350-1600. Norman: University of Oklahoma Press, 2014. 
Quezada, Sergio e Inés Ortiz Yam. Visita de Diego García de Palacio a Yucatán, 1583. México: Universidad Nacional Autónoma de México, 2009.

Quezada, Sergio y Anabel Torres Trujillo. Tres nobles mayas yucatecos. Mérida: Instituto de Cultura de Yucatán, 2010.

Quezada, Sergio y Tsubasa Okoshi Harada. Los papeles de los Xiu de Yaxá, Yucatán. México: Universidad Nacional Autónoma de México, 2001.

Ramos, Gabriela y Yanna YannaKaKIs, eds. Indigenous Intellectuals: Knowledge, Power, and Colonial Culture in Mexico and the Andes. Durham y Londres: Duke University Press, 2014.

Restall, Matthew. "Gaspar Antonio Chi: Bridging the Conquest of Yucatán”. En The Human Tradition in Colonial Latin America, ed. Adrien Kenneth J., 6-21. Wilmington: Scholarly Resources, 2002.

Ruigómez Gómez, Carmen. Una politica indigenista de los Habsburgo: el Protector de Indios en el Perú. Madrid: Ediciones de Cultura Hispánica, 1988.

Solís Robleda, Gabriela y Pedro Bracamonte y Sosa. Cedulario de la dominación española en Yucatán, siglo XVI. Mérida: Colección Peninsular, Memoria Documental, 2010.

YANNAKAKIs, Yanna. "Making Law Intelligible: Networks of Translation in Mid-Colonial Oaxaca”. En Indigenous Intellectuals, ed. Ramos y Yannakakis, 79-106. 